\title{
Bony orbital morphology in neurofibromatosis type 1 (NF1)
}

\author{
Sue C Kaste, Eniko K Pivnick
}

\begin{abstract}
We retrospectively compared patients with NF1 with and without optic pathway gliomas (OPG) to determine the incidence and range of orbital developmental abnormalities and compared the incidence of OPG in African-Americans and whites. From cranial MR scans, we manually measured 14 orbital dimensions, compared them to published standards of Waitzman et al, calculated orbital volumes, and determined the presence or absence of volumetric symmetry $(\Delta v)$ $\left(\Delta v \leqslant 0.3 \mathrm{~cm}^{3}\right.$ was considered to be symmetrical). We compared the results of orbital configurational assessment between patients with (group I) and those without OPG (group II). The study population comprised 58 patients, 24 boys, 18 African-American, and one Hispanic. Median age at imaging was 7 years (range 0.525.5 years). Fifty-eight percent had conformational abnormalities, 16 of whom had more than one abnormality ( $28 \%$ ), the most frequent being increased intertemporal distance $(n=10)$, increased lateral orbital distance $(n=8)$, increased medial wall length $(n=6)$, and decreased medial wall length $(n=6)$. The increased intertemporal and lateral orbital distances may contribute to the appearance of hypertelorism. Only two patients had sphenoid wing hypoplasia. We found a high incidence of orbital dimensional abnormalities in the total population but more often saw multiple abnormalities in patients with OPG. However, no pattern of configurational abnormality emerged. OPG is less frequent in African-Americans. Orbital volumetric disparity seems to be independent of the presence of OPG. ( $\mathcal{}$ Med Genet 1998;35:628-631)
\end{abstract}

Keywords: neurofibromatosis type 1; orbital morphology; MRI

Dr Kaste, Diagnostic

Imaging, St Jude Research

Hospital, 332 N Lauderdale,

Memphis, TN 38105, USA.

Received 22 December 1997 Revised version accepted for publication 9 February 1998

Neurofibromatosis type 1 (NF1) or von Recklinghausen neurofibromatosis is one of the most common autosomal dominant disorders in man, primarily affecting cells of neural crest origin and resulting in developmental, pigmentary, and neoplastic abnormalities. Developmental defects of the skull and the facial bones are commonly seen in association with NF1 and macrocephaly is the most prevalent and familiar. ${ }^{1}$ The most distinctive craniofacial bone dysplasia in NF1 involves the sphenoid wings. Sphenoid wing hypoplasia is almost always unilateral and involves the greater wing of the sphenoid bone. The incidence of sphenoid dysplasia ranges from $4-58 \%$ of NF1 patients. ${ }^{2-6}$ However, patients with NF1 are known to have other osseous craniofacial aberrations, which include simple skull asymmetry, localised defects of the parietal and occipital bones of various sizes, ${ }^{7}$ deformity of the lateral aspect of the sphenoid body, widened middle cranial fossa and sella turcica, ${ }^{5-11}$ petrous bone dysplasia, enlarged outline of the orbit and frontal dysplasia with lateral enlargement of the frontal sinus as opposed to hypoplasia of the other sinuses, ${ }^{12}{ }^{13}$ maxillary sinus asymmetry, ${ }^{14}$ maxillo-zygomatico-temporomandibular hypoplasia, and hypertelorism..$^{15} 16$

To determine the incidence and range of orbital developmental abnormalities of patients with NF1, we retrospectively reviewed cranial MRI in the clinical populations of NF1 patients with and without optic pathway tumours.

\section{Materials and methods}

The study population comprised 58 patients with NF1 (39 whites, one Hispanic, 18 African-American) who had been evaluated at St Jude Children's Research Hospital (SJCRH) or LeBonheur Children's Medical Center (LBCMC) between 1984 and 1997, and for whom cranial MR scans were available for review. The study cohort was drawn from an available population of 255 children with NF1, 55 of whom were African-American.

Orbital volumes and dimensions were manually measured from previously acquired axial cranial MRI studies. We chose a single image through the orbits at the level of the optic nerve and manually measured 14 orbital dimensions based on the published standards by Waitzman et $a l^{17}$ (table 1). We calculated orbital volumes

Table 1 Definition of terms ${ }^{\prime \prime}$

\begin{tabular}{ll}
\hline Dimension & Description \\
\hline Lateral orbital distance & Distance between anterior tips of the lateral orbital walls \\
Anterior interorbital distance & Distance between the anterior ends of the medial orbital walls \\
Mid interorbital distance & Distance across the ethmoid bone, midway between the optic strut base and the lacrimal bone \\
Intertemporal distance & Distance between the most medial aspect of the greater sphenoid wing \\
Medial orbital wall length & Distance between the lacrimal bone and optic strut base \\
Lateral orbital wall length & Distance from base of the optic strut and the most anterior tip of the lateral orbital wall \\
Lateral orbital angle & The angle defined by the sagittal axis and a line from the most anterior and posterior tips of the lateral orbital wall \\
\hline
\end{tabular}


Table 2 Comparison of patient characteristics, volumetric asymmetry, and dimensional abnormalities in patients with neurofibromatosis type 1

\begin{tabular}{lll}
\hline No of patients & $\begin{array}{l}\text { Group I (patients } \\
\text { without OPG) }\end{array}$ & $\begin{array}{l}\text { Group II (patients with } \\
\text { OPG) }\end{array}$ \\
\hline Total evaluated & 38 & 20 \\
With NF1 lesions & $15(39 \%)$ & $17(85 \%)$ \\
Who received orbital or cranial irradiation & 0 & 9 \\
With orbital volumetric asymmetry & $26(68 \%)$ & $14(70 \%)$ \\
& Range $0.4-6.5 \mathrm{~cm}^{3}$ & Range $0.4-7.7 \mathrm{~cm}^{3}$ \\
With increased dimensions & $14(37 \%)$ & $10(5 \%)$ \\
With decreased dimensions & $7(18 \%)$ & $7(35 \%)$ \\
With multiple dimensional abnormalities & $7(18 \%)$ & $9(45 \%)$ \\
Sphenoid wing dysplasia & $1(3 \%)$ & $1(5 \%)$ \\
\hline
\end{tabular}
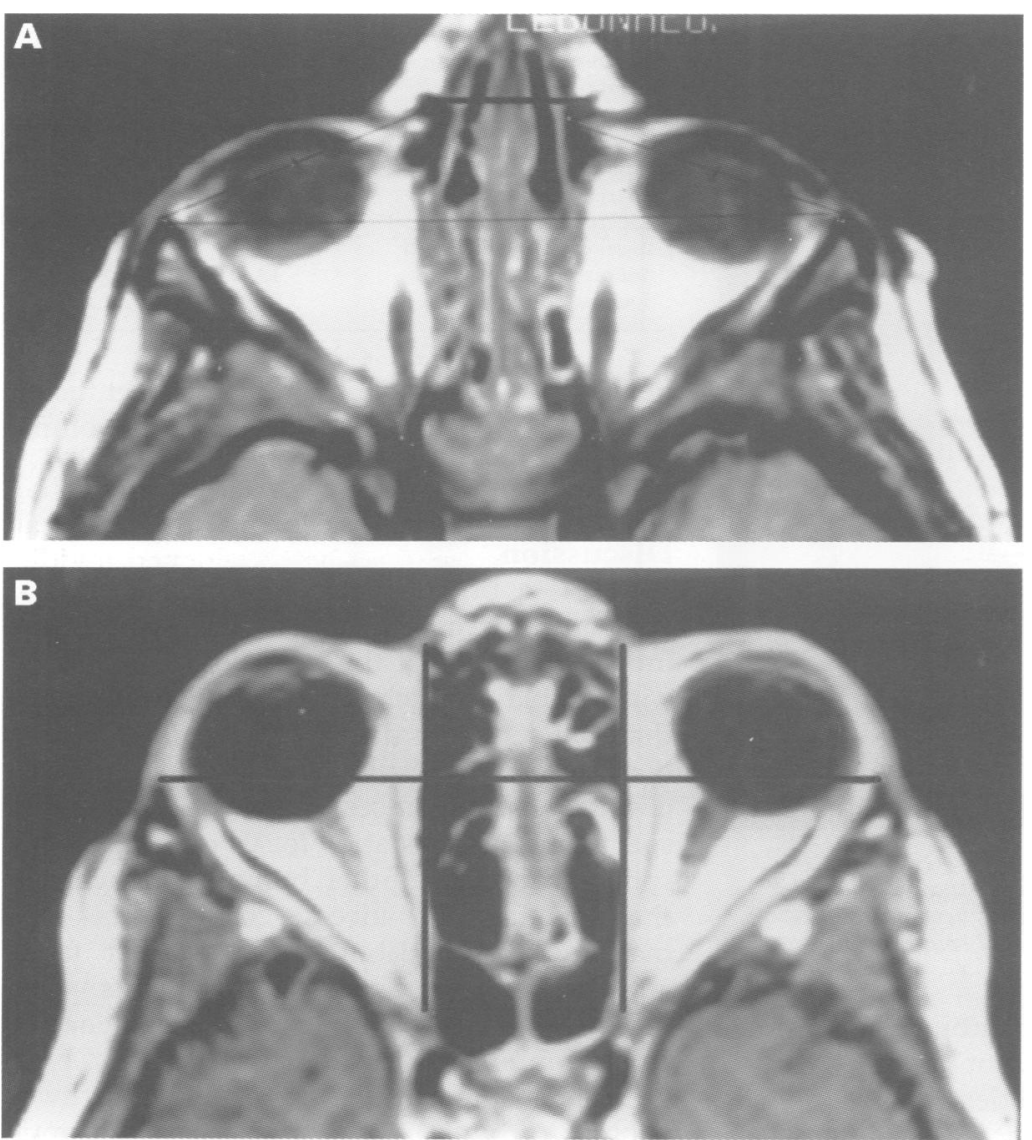

Figure 1 Examples of abnormal orbital dimensions in groups I and II. (A) A 5 year old boy (group I) with symmetrical orbital volumes but with increased anterior orbital distance (heavy black line). (B) A 7 year old boy (group II) with symmetrical orbital volumes but with increased medial wall lengths bilaterally (vertical lines) and increased transorbital dimension (horizontal line).
Table 3 Distribution of dimensional abnormalities of patients with neurofibromatosis type 1

\begin{tabular}{|c|c|c|}
\hline Measured dimension & $\begin{array}{l}\text { Group I } \\
\text { (patients } \\
\text { without OPG) }\end{array}$ & $\begin{array}{l}\text { Group II } \\
\text { (patients } \\
\text { with OPG) }\end{array}$ \\
\hline \multicolumn{3}{|l|}{ Lateral orbital distance } \\
\hline Increased dimension & 5 & 3 \\
\hline Decreased dimension & 0 & 3 \\
\hline \multicolumn{3}{|c|}{ Anterior interorbital distance } \\
\hline Increased dimension & 4 & 2 \\
\hline Decreased dimension & 1 & 1 \\
\hline \multicolumn{3}{|l|}{ Mid interorbital distance } \\
\hline Increased dimension & 3 & 2 \\
\hline Decreased dimension & 0 & 0 \\
\hline \multicolumn{3}{|l|}{ Intertemporal distance } \\
\hline Increased dimension & 6 & 4 \\
\hline Decreased dimension & 0 & 2 \\
\hline \multicolumn{3}{|l|}{ Lateral orbital angle } \\
\hline Increased dimension & 1 & 0 \\
\hline Decreased dimension & 0 & 0 \\
\hline \multicolumn{3}{|l|}{ Medial orbital wall length } \\
\hline Increased dimension & 2 & 4 \\
\hline Decreased dimension & 6 & 0 \\
\hline \multicolumn{3}{|l|}{ Lateral orbital wall length } \\
\hline Increased dimension & 1 & 4 \\
\hline Decreased dimension & 2 & 2 \\
\hline
\end{tabular}

patients (39\%) had intracranial NF1 lesions (UBOs). Five patients had received radiation therapy for intracranial tumours before imaging for this study. Twenty-six patients $(68 \%)$ had a median orbital volumetric asymmetry of $0.8 \mathrm{~cm}^{3}$ (range 0.4 to $6.5 \mathrm{~cm}^{3}$ ). Twenty-one $(55 \%)$ patients had abnormal orbital dimensions (14 with increased dimension and seven with decreased dimension), and seven (18\%) had multiple dimensional abnormalities (table 2 , figs $1 \mathrm{~A}$ and $2 \mathrm{~A}$ ). Only one of the five patients who received cranial irradiation had abnormal orbital dimensions and this comprised decreased lateral orbital wall lengths bilaterally.

PATIENTS WITH OPTIC PATHWAY GLIOMAS (GROUP II)

The 20 patients comprising group II ranged in age from 0.5 to 24.5 years (median 8.1 years) at the time of imaging. Six were males, 14 were females, one $(5 \%)$ was Hispanic, two $(10 \%)$ were African-American, and $17(85 \%)$ were white. The prevalence of OPG in AfricanAmerican patients was less than that observed among the remaining patients of other racial origins in the study group, $11 \% v 45 \%$, respectively $(\mathrm{p}<0.012)$.

One patient had unilateral sphenoid wing hypoplasia. In this group, 17 patients $(85 \%)$ had NF1 lesions (UBOs) of the brain. Two patients also had brainstem glioma, one patient underwent unilateral optic nerve resection for optic pathway glioma, and four patients had received orbital or cranial radiation for treatment of OPG or intracranial tumours before imaging. Of the four patients who received cranial or orbital irradiation, only one had unilateral decrease in the lateral orbital wall length.

OPGs were confined to the optic chiasm in two cases (both with bilateral involvement) and to the orbits in four (of which one case had unilateral involvement). The remaining 14 cases $(70 \%)$ had involvement of both the intraorbital optic nerves and the optic chiasm. Eight of these 14 had symmetrical involvement and only one had unilateral involvement.

Fourteen patients ( $70 \%)$ in group II had a median orbital volume asymmetry of $1.1 \mathrm{~cm}^{3}$ at the time of imaging; 18 were males, 20 females, $16(42 \%)$ were African-American, and $22(58 \%)$ were white. One patient had unilateral sphenoid wing hypoplasia. Fifteen 

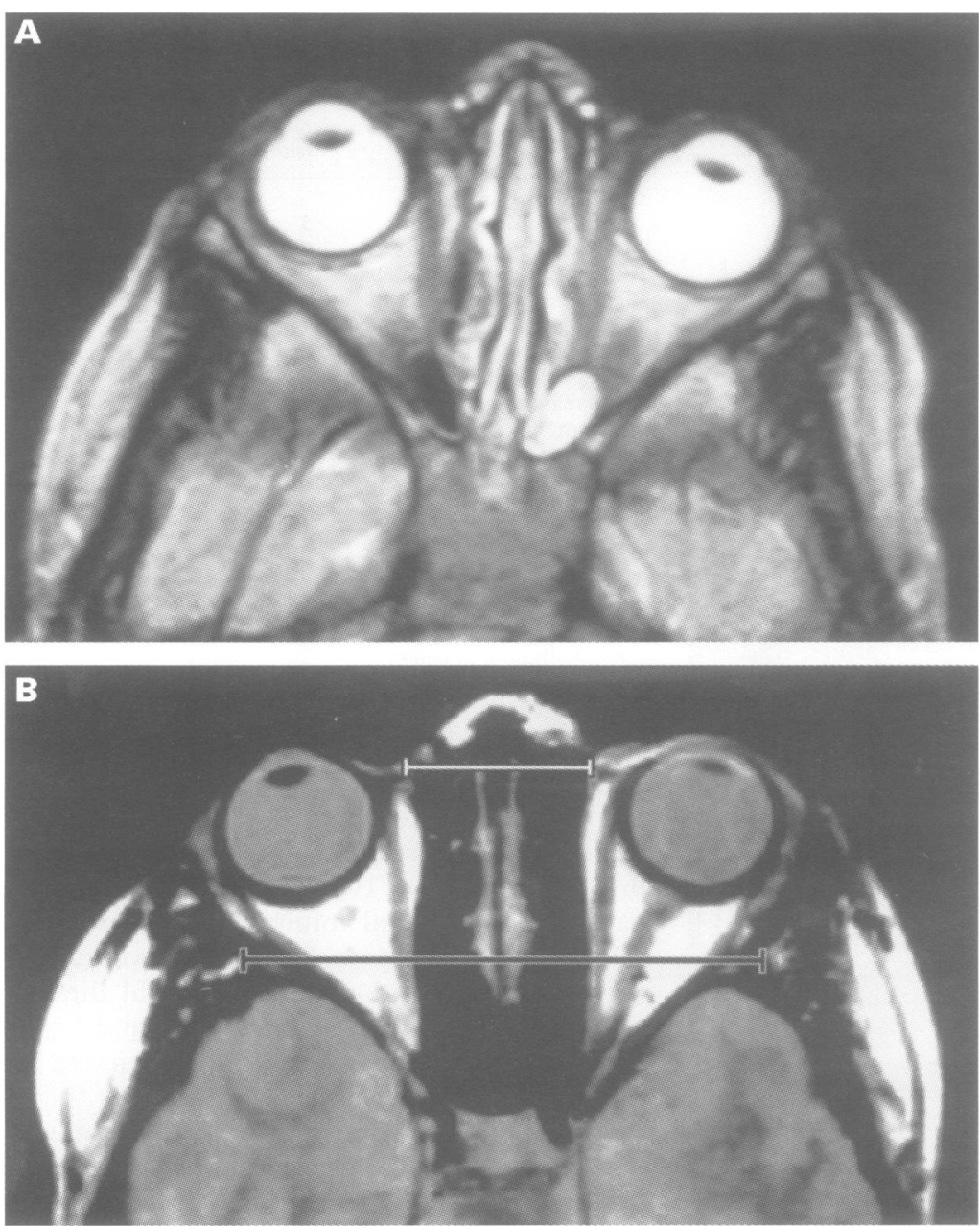

Figure 2 Examples of orbital volumetric disparity in groups $I$ and II. (A) $A 5$ year old boy (group $I$ ) with asymmetrical orbital volumes (OD $2.8 \mathrm{~cm}$ larger than $O S$ ). He has no other dimensional aberrations. (B) A 6 year old girl (group II) with asymmetrical orbital volumes (OD $5.2 \mathrm{~cm}$ smaller than $O S)$. She also has an increase in both the anterior (white line) and lateral interorbital distances (black line).

(range 0.4 to $7.7 \mathrm{~cm}^{3}$ ). Orbital dimensional abnormalities were present in 17 patients $(85 \%)$. Ten of the 17 patients had increased dimensions, seven had decreased dimensions, and one had both increased and decreased dimensions. Nine patients ( $45 \%)$ had multiple dimensional abnormalities (table 3 , figs $1 \mathrm{~B}$ and 2B).

ORBITAL SYMMETRY AND ORBITAL DIMENSIONS IN AFRICAN-AMERICAN AND WHITE PATIENTS

Eleven of the 18 African-American patients had abnormal orbital dimensions (61\%). Seven of these 11 patients had increased dimensions (64\%) and three patients had decreased dimensions $(27 \%)$. None had both increased and decreased dimensions. The most common abnormalities were an increased intertemporal distance $(n=3)$ and increased lateral orbital dimension $(n=4)$.

Twenty-three of the 39 white patients had abnormal orbital dimensions (59\%). A total of 15 patients had increased dimensions (65\%). The most common abnormalities were increased intertemporal distance $(n=7)$, increased lateral temporal distance $(n=5)$, and increased anterior interorbital distance $(n=5)$. There were seven patients who had decreased dimensions $(30 \%)$ and two who had a combination of decreased and increased di-
Table 4 Comparison of orbital symmetry and orbital dimensions in African-American and white patients with neurofibromatosis type 1

\begin{tabular}{|c|c|c|}
\hline Measured dimension & $\begin{array}{l}\text { African- } \\
\text { American }\end{array}$ & White \\
\hline \multicolumn{3}{|l|}{ Lateral orbital distance } \\
\hline Increased dimension & 4 & 5 \\
\hline Decreased dimension & 0 & 3 \\
\hline \multicolumn{3}{|c|}{ Anterior interorbital distance } \\
\hline Increased dimension & 1 & 5 \\
\hline Decreased dimension & 0 & 2 \\
\hline \multicolumn{3}{|l|}{ Mid interorbital distance } \\
\hline Increased dimension & 2 & 3 \\
\hline Decreased dimension & 0 & 0 \\
\hline \multicolumn{3}{|l|}{ Intertemporal distance } \\
\hline Increased dimension & 3 & 7 \\
\hline Decreased dimension & 0 & 2 \\
\hline \multicolumn{3}{|l|}{ Lateral orbital angle } \\
\hline Increased dimension & 1 & 0 \\
\hline Decreased dimension & 0 & 0 \\
\hline \multicolumn{3}{|l|}{ Medial orbital wall length } \\
\hline Increased dimension & 1 & 2 \\
\hline Decreased dimension & 3 & 2 \\
\hline \multicolumn{3}{|l|}{ Lateral orbital wall length } \\
\hline Increased dimension & 1 & 3 \\
\hline Decreased dimension & 0 & 2 \\
\hline
\end{tabular}

mensions (8\%). There was no significant difference in the orbital median volume between the races (table 4 ).

\section{Discussion}

There is a broad spectrum of facial skeletal aberrations among patients with NF1. At the most severe end of this spectrum is sphenoid wing dysplasia which may progress to a severity that will seriously disrupt the integrity of the bony orbit and result in serious medical and cosmetic consequences. At the other end of the spectrum, mild, static, local lesions of the sphenoid bone or other bony components of the orbit have no adverse consequences and may merely contribute to a distinct facial appearance in some of the NF1 patients. ${ }^{7}$

In this study we examined the incidence of orbital abnormalities in two groups of NF1 patients: (1) patients without optic pathway gliomas (group I) and (2) patients with optic pathway gliomas (group II) and we compared these patients to normal standards. There was a significantly increased incidence of conformational abnormalities present in both NF1 groups as compared to normal controls. Although no specific pattern of configurational abnormality emerged, there was a trend towards increased distance between the orbits. The most common abnormalities in both NF1 groups were the increased transorbital diameter, intertemporal distance, anterior interorbital distance, and mid interorbital distance, all of which probably contribute to the hypertelorism observed in many patients with NF1.

Multiple conformational abnormalities were more frequent in patients with OPG than in those without OPG. Though our study populations are small, these findings suggest that more numerous and severe developmental abnormalities manifest in patients with the more severe phenotypic expression (that is, OPG).

There was a notable difference in the incidence of UBOs, increased signals on T2 weighted images, between groups I and II. These foci of altered signal were seen more 
commonly in the OPG group (group II) than in those without OPGs (group I). The clinical significance of UBOs is not well known. As NF1 patients who develop OPGs have more UBOs than patients without OPGs, the increased incidence of UBOs in patients in the OPG group may reflect the severity of the disease process. The association of UBOs and OPG must be approached with caution. In as much as patients with OPG tend to undergo more frequent neuroimaging than those without OPG, the increased frequency of UBOs in group II may reflect imaging bias.

There was a significant difference in the racial distribution between groups I and II. Group I comprised 16 African-Americans $(42 \%)$ in contrast to group II comprising only two $(10 \%)$ African-Americans $(p<0.012)$. These data support the observations made by others that there are racial differences in the incidence of optic pathway tumours in NF1. ${ }^{7021}$ However, when we compared orbital symmetry and orbital dimensions in AfricanAmerican and white patients, we found no significant difference between the two groups.

Both study groups displayed orbital volumetric disparity to the same degree, thereby suggesting that orbital volumetric inequality is independent of the presence of OPG, and that volumetric asymmetry is a manifestation of the potential for growth disturbances in patients with NF1. Further, by the preponderance of patients with extensive OPGs (that is, involving both the optic chiasm and orbits), any possible effect on orbital growth that may result from the distribution of OPGs would have been exaggerated. Though a total of nine patients from both study groups had received orbital or cranial irradiation, only two had decreased orbital dimensions and a third had an increased dimension. We do not believe that the facial developmental aberrations (that is, the prevailing increased orbital dimensions) are necessarily related to radiation therapy in that orbital irradiation decreases bony orbital growth..$^{22-25}$

The observations of this study suggest that the NF1 gene plays an important role in the embryonic development of the orbit. We propose that the orbital developmental abnormalities in NF1 are more prevalent and show a wider spectrum than was previously appreciated. Orbital abnormalities, as a skeletal substrate, may contribute to the characteristic NF1 facial appearance in some cases. Larger studies and correlation with genotype will be needed to understand this complex syndrome better.
We are grateful to Dr Vincent M Riccardi for his comments on this paper. We thank Dr Elizabeth A Tolley for the statistical analysis. This work was supported by grants P30 CA-21765 and PO1 CA-23099 from the National Cancer Institute, by the American Lebanese Syrian Associated Charies (AI (ALSAC) (SCK), from the Herbert and Mary Shainberg Neuroscience's Research Program, and the Crippled Children's Foundation Research Center Grant at the LeBonheur Children's Medical Center from Memphis Tennessee (EKP).

1 Huson SM, Harper PS, Compston DAS. Von Recklinghausen neurofibromatosis: a clinical and population study in South East Wales. Brain 1988;111:1355-81.

2 Burrows EH. Bone changes in orbital neurofibromatosis. $\mathrm{Br}$ 7 Radiol 1963;36:549-61.

3 Jacoby CG, Go RT, Beren RA. Cranial CT of neurofibromatosis. AfR 1980;135:553-7.

4 Hunt JC, Pugh DG. Skeletal lesions in neurofibromatosis. Radiology 1961;76:1-19.

5 Zimmerman RA, Bilaniuk LT, Metzger RA, Grossman RI, Schut L, Bruce DA. Computed tomography of orbitalfacial neurofibromatosis. Radiology 1983;146:113-16.

6 Bognanno JR, Edwards MK, Lee TA, Dunn DW, Roos KL Klatte EC. Cranial MR imaging in neurofibromatosis. $A \mathcal{F} R$ 1988;151:381-8.

7 Riccardi VM. Neurofibromatosis: phenotype, natural history and pathogenesis. 2nd ed. Baltimore: The John Hopkins University Press, 1992.

8 Rootman J, Robertson W. Tumors. In: Rotman J, ed. Disease of the orbit. New York: J B Lippincott, 1988

9 Binet EF, Kieffer SA, Martin SH, Peterson HO. Orbital dysplasia in neurofibromatosis. Radiology 1969;93:829-33.

10 Moore RF. Diffuse neurofibromatosis with proptosis. $\mathrm{Br} F$ Ophthalmol 1993;15:272-9.

11 LeWald LT. Congenital absence of the superior orbital wall associated with pulsating exophthalmos. AFR 1933;30:75664.

12 Gardeur D, Palmieri A, Mashaly R. Cranial computed tomography in the phakomatoses. Neuroradiology 1983;25:293304.

13 Murtaugh FR, Boyd RE, Okusski TA. Internal auditory canal flaring in neurofibromatosis without acoustic neuroma. Arch Neurol 1980;37:785.

14 DiMario FJ, Bowers P, Jagivan B, Burleson J, Langshur S Greenstein RM. Analysis of skull anthropometric measurements in patients with neurofibromatosis type-1. Invest Radiol 1992;28:116-20.

15 Westerhof W, Delleman JW, Wolters E, Dijkstra P. Neurofibromatosis and hypertelorism. Arch Dermatol 1984;120: 1579-81.

16 Wolters EC, Westerhof W, Delleman JW, Dijkstra P. Hypertelorism in neurofibromatosis. Neuropediatrics 1986;17 175-7.

17 Waitzman AA, Posnick JC, Armstrong DC, et al. Craniofacial skeletal measurements based on computer tomography. Part II. Normal values and growth trends. Cleft Palate Craniofac F 1992;29:118-28.

18 Kennedy RE. The effect of early enucleation on the orbit in animals and humans. F Ophthalmol 1965;60:277-306.

19 Newton TH, Potts DG. Radiology of the skull and brain. Vol 1, book 2. St Louis: Mosby, 1971:465-9.

20 Saal HM, Schorry EK, Lovell AM, et al. Racial differences in the prevalence of optic nerve gliomas in neurofibromatosis type 1. Am 7 Hum Genet 1995;280:A54.

21 Pletcher BA, Magee MI, Frohman IP, et al. Conformation of decreased risk of optic glioma in African Americans with NF type I. Am $\mathcal{F}$ Hum Genet Suppl 1996;59:A101.

22 Kaste SC, Chen G, Fontanesi J, Crom DB, Pratt CB. Orbital development in longterm survivors of retinoblastoma. F Clin Oncol 1997;15:1183-9.

23 Guyuron B, Dagys AP, Munro IR, et al. Effect of irradiation on facial growth: a 7- to 25-year follow-up. Ann Plastic Surg 1983;11:423-7.

24 Egawa S, Tsukiyama I, Akine Y, et al. Supression of bony growth of the orbit after radiotherapy for retinoblastoma. Radiat Med 1987;5:207-11.

25 Ju DMC, Moss M, Crikelair GF. Effect of radiation on the development of facial structures in retinoblastoma cases. Am $\mathcal{F}$ Surg 1963;106:807-15. 